\title{
Calcium-free vitrification reduces cryoprotectant-induced zona pellucida hardening and increases fertilization rates in mouse oocytes
}

\author{
Mark G Larman, Courtney B Sheehan and David K Gardner \\ Colorado Center for Reproductive Medicine, 799 East Hampden Avenue, Suite 520, Englewood, Colorado 80113, \\ USA
}

Correspondence should be addressed to D K Gardner; Email: dgardner@colocrm.com

\begin{abstract}
Despite the success of embryo cyropreservation, routine oocyte freezing has proved elusive with only around 200 children born since the first reported birth in $\mathbf{1 9 8 6}$. The reason for the poor efficiency is unclear, but evidence of zona pellucida hardening following oocyte freezing indicates that current protocols affect oocyte physiology. Here we report that two cryoprotectants commonly used in vitrification procedures, dimethyl sulfoxide (DMSO) and ethylene glycol, cause a large transient increase in intracellular calcium concentration in mouse metaphase II (MII) oocytes comparable to the initial increase triggered at fertilization. Removal of extracellular calcium from the medium failed to affect the response exacted by DMSO challenge, but significantly reduced the ethylene glycol-induced calcium increase. These results suggest that the source of the DMSO-induced calcium increase is solely from the internal calcium pool, as opposed to ethylene glycol that causes an influx of calcium across the plasma membrane from the external medium. By carrying out vitrification in calcium-free media, it was found that zona hardening is significantly reduced and subsequent fertilization and development to the two-cell stage significantly increased. Furthermore, such calcium-free treatment appears not to affect the embryo adversely, as shown by development rates to the blastocyst stage and cell number/allocation. Since zona hardening is one of the early activation events normally triggered by the sperm-induced calcium increases observed at fertilization, it is possible that other processes are negatively affected by the calcium rise caused by cryoprotectants used during oocyte freezing, which might explain the current poor efficiency of this technique.

Reproduction (2006) 131 53-61
\end{abstract}

\section{Introduction}

The ability to routinely cryopreserve human oocytes will have a significant impact on assisted reproductive technology (ART). Changes in government guidelines in certain countries now restrict the number of oocytes that can be inseminated. This means there is now an increased need for gamete cryopreservation. Furthermore, not only will oocyte cryopreservation circumvent the ethical and legal problems associated with embryo freezing, but it will also benefit numerous patient groups including women at risk of ovarian function loss through premature menopause, surgical treatments or radio/chemotherapy (for review see Falcone et al. 2004). An increasing number of women are deciding to delay starting a family and although currently controversial, one could envisage cryostorage of oocytes from younger women to alleviate the problems associated with maternal ageing and the sharp drop in egg quality that occurs between 30 and 40 years of age.
Currently, there are two techniques employed for cryopreservation - slow-freezing and vitrification. The principal difference between these two procedures, when using the same freezing straws, is the rate of cooling (approximately $1 \mathrm{vs}>1000^{\circ} \mathrm{C} / \mathrm{min}$ respectively). For both protocols, first the cells must be treated with a combination of cell-permeating and non-permeating agents to minimize ice formation that can severely damage the cell. Previously, high concentrations of cryoprotectant were required for vitrification, but novel containers and submicroliter volumes result in super-fast cooling and subsequent warming rates $\left(>20000^{\circ} \mathrm{C} / \mathrm{min}\right.$; Steponkus et al. 1990, Mukaida et al. 2001) so that concentrations closer to those used in slow-freezing can now be used (Mukaida et al. 2002, Kasai \& Mukaida 2004).

Embryo freezing has been implemented very successfully in ART and now allows supernumerary embryos generated through in vitro fertilization (IVF) to be routinely 
frozen and stored (Liebermann 2003, Veeck 2003). Blastocysts thawed and subsequently transferred yield an acceptable pregnancy rate, which demonstrates that cryopreserved human blastocysts do not have a dramatic loss of viability (Gardner et al. 2003, Leibo 2004, Veeck et al. 2004). However, the oocyte has proved to be far more troublesome (Coticchio et al. 2004). Chen (1986) reported the first pregnancy following IVF of a cryopreserved human oocyte. Despite this, to date only around 200 children have resulted from oocyte cryopreservation techniques (Leibo 2004). Together with the fact that the number of births per number of oocytes frozen is typically no greater than $3 \%$, it is clear that oocyte cryopreservation is an inefficient process at present.

The stark difference between the success of oocyte and embryo cryopreservation has yet to be strictly explained, but differences in cell size and membrane permeability have been proposed (Leibo 2004, Stachecki \& Cohen 2004). The oocyte is unique in that the maternal DNA is held suspended in the cytoplasm on the meiotic spindle and not within the protective confines of the nuclear membrane, as it is for the majority of the time during subsequent preimplantation development. Damage to the DNA and/or microtubules could explain the limited success of oocyte cryopreservation. However, a further consideration is that the oocyte is arrested in a state primed for activation and changes in its environment can cause parthenogenetic activation.

A current potential problem with oocyte freezing is the induction of a primary activation event, zona hardening, which significantly inhibits IVF (Matson et al. 1997) and may affect subsequent implantation. Zona hardening is brought about by fusion of cortical granules to the plasma membrane and the release of their contents into the zona pellucida layers (for review see Sun 2003). The membrane fusion event is calcium-dependent and is normally triggered by the increase in intracellular calcium initiated by sperm-egg fusion (Kline \& Kline 1992). Upon fusion, the sperm triggers a series of calcium oscillations. The initial calcium increase lasts for around $5 \mathrm{~min}$ and causes the cortical granules to fuse with the plasma membrane and release their contents into the zona pellucida layers (Tahara et al. 1996). Proteolytic enzymes target sperm binding proteins to prevent further sperm from fertilizing the egg. Zona hardening can be overcome by intracytoplasmic sperm injection (ICSI) (Porcu et al. 2000), but the fact that the oocyte has undergone the cortical granule reaction indicates that the oocyte has been artificially activated prior to actual fertilization. This could, therefore, explain the poor efficiency of oocyte freezing, for even though a sperm is injected via ICSI, the oocyte has already begun its activation events such as cortical granule exocytosis and possible down-regulation of cell cycle control proteins.

It has previously been reported that the cryoprotectant dimethyl sulfoxide (DMSO) causes zona hardening and a reduced rate of fertilization (Vincent et al. 1991). The effect of DMSO is not directly on the zona, but requires the presence of the oocyte (Vincent et al. 1990). DMSO reduces the number of cortical granules (Vincent et al. 1991), suggesting that the DMSO-induced zona hardening is caused by cortical granule exocytosis. Since DMSO has been shown to cause a transient intracellular calcium rise in various cell lines (Morley \& Whitfield 1993) and fusion of cortical granules to the oocyte plasma membrane is calcium-dependent (Kline \& Kline 1992, Tahara et al. 1996), it is tempting to suggest that DMSO triggers cortical granule release by increasing intracellular calcium. DMSO appears not to be the only cryoprotectant that increases calcium since high concentrations of ethylene glycol (EG, 10-40\%) have been shown recently to increase intracellular calcium in mouse oocytes (Takahashi et al. 2004).

Therefore, we have investigated whether exposure to cryoprotectants causes a calcium increase that leads to zona hardening. The data presented here show that the two cryoprotectants used in vitrification protocols, DMSO and EG, cause large transient increases in intracellular calcium in mouse oocytes. The increase in calcium is sufficient to cause zona hardening, which significantly reduces fertilization. By making the vitrification medium nominally calcium-free we have determined that zona hardening is significantly reduced, which allows IVF without the use of ICSI or laser-assisted zona removal. Furthermore, calcium-free vitrification does not seem to affect embryo developmental rates and cell number/allocation.

\section{Materials and Methods}

Unless otherwise stated all Materials were obtained from Sigma Chemical Co. (St Louis, MO, USA). This work received prior approval from the Institutional Animal Care and Users Committee. Sperm was collected from 12- to 20-week-old F1 (C57BL/6 × CBA) male mice and oocytes were collected from 4- to 5-week-old F1 $(\mathrm{C} 57 \mathrm{BL} / 6 \times$ $\mathrm{CBA} / \mathrm{Ca}$ ) female mice (Jackson Laboratory, Bar Harbor, ME, USA). Female mice were administered 5 iu pregnant mare's serum gonadotropin and 48-52 h later 5 iu human chorionic gonadotropin (hCG) were administered. Oocytes were collected 12.5-13.5 h post-hCG and denuded by incubation in G-MOPS (Lane \& Gardner 2004) (supplemented with $5 \mathrm{mg} / \mathrm{ml}$ human serum albumin (HSA)) with $0.5 \mathrm{mg} / \mathrm{ml}$ hyaluronidase. Oocytes were washed three times and held in droplets of G-MOPS under Ovoil (Vitrolife, Gothenburg, Sweden) at $37^{\circ} \mathrm{C}$.

Intracellular calcium changes were monitored by loading the oocytes with $10 \mu \mathrm{molI}^{-1}$ Indo-1 AM (Molecular Probes, Eugene, OR, USA) for $30 \mathrm{~min}$. The loading media included $250 \mu \mathrm{mol} \mathrm{I}^{-1}$ sulfinpyrazone to reduce dye compartmentalization and extrusion (Lawrence et al. 1997). Single oocytes were held in G-MOPS with or without calcium (with a holding pipette) in a heated chamber on a Nikon TE300 microscope equipped with an SFX-2 microfluorimeter (Solamere Technology Group, Salt Lake City, UT, USA). Oocytes were incubated in calcium-free 
G-MOPS for 30 min before cryoprotectant exposure. Solutions without calcium were termed 'nominally-free' since calcium was simply omitted from the stock solution. To ensure rapid exposure that would best mimic the vitrification procedure, oocytes were held in a small droplet (approx. $20 \mu \mathrm{l}$ ) of G-MOPS before $980 \mu \mathrm{l}$ of the cryoprotectant solution (made up in G-MOPS with $12 \mathrm{mg} / \mathrm{ml} \mathrm{HSA}$ ) was added to the heated chamber $\left(37^{\circ} \mathrm{C}\right)$.

Vitrification and warming were carried out at $37^{\circ} \mathrm{C}$ in a base solution of G-MOPS supplemented with $12 \mathrm{mg} / \mathrm{ml}$ HSA. Vitrification was carried out using a two-step method and cryoloop, as previously described (Lane \& Gardner 2001). Briefly, oocytes were placed in the initial cryoprotectant solution $(8 \% \mathrm{DMSO}, 8 \% \mathrm{EG} \mathrm{v} / \mathrm{v}$; equates to $1.13 \mathrm{moll}^{-1}$ DMSO, $\left.1.43 \mathrm{moll}^{-1} \mathrm{EG}\right)$ for $1 \mathrm{~min}$. Oocytes were then moved to the second solution (16\% DMSO, $16 \% \mathrm{EG} \mathrm{v} / \mathrm{v}, 0.65 \mathrm{~mol} \mathrm{I}^{-1}$ sucrose; equates to $2.25 \mathrm{~mol} \mathrm{I}^{-1}$ DMSO, $2.86 \mathrm{moll}^{-1} \mathrm{EG}$ ) for less than $30 \mathrm{~s}$ before being pipetted onto a cryoloop, which had been preloaded with this solution. The cryoloop was then plunged into a cryovial filled with liquid nitrogen to facilitate vitrification. For warming, oocytes were moved through $1 \mathrm{ml}$ serial dilutions of sucrose $\left(0.25 \mathrm{~mol} \mathrm{I}^{-1}\right.$ for $1 \mathrm{~min} ; 0.125 \mathrm{~mol} \mathrm{I}^{-1}$ for $2 \mathrm{~min}$; $0 \mathrm{moll}^{-1}$ for $5 \mathrm{~min}$ ) to reduce osmotic stress (Lane \& Gardner 2001). Oocytes were allowed to recover for $1 \mathrm{~h}$. At this stage oocytes were either fertilized or the degree of zona hardening was determined.

To load the calcium chelator 1,2-bis(o-aminophenoxy)ethane- $\mathrm{N}, \mathrm{N}, \mathrm{N}^{\prime}, \mathrm{N}^{\prime}$-tetraacetic acid (BAPTA-AM), oocytes were incubated with $10 \mu \mathrm{molI}^{-1}$ BAPTA-AM (Molecular Probes) for $30 \mathrm{~min}$. For zona hardening assessment, oocytes were transferred to a $1 \% \mathrm{w} / \mathrm{v}$ solution of chymotrypsin (in G-MOPS) on a heated stage $\left(37^{\circ} \mathrm{C}\right)$ and the integrity of the zona pellucida was monitored over time, the end point being when the zona was no longer clearly visible (Matson et al. 1997). For fertilization, oocytes were transferred to G-FERT (Vitrolife). Twenty oocytes were placed in $20 \mu \mathrm{l}$ droplets of G-FERT. One microliter sperm suspension that had been allowed to capacitate for $2 \mathrm{~h}$ in $1 \mathrm{ml} \mathrm{G-FERT} \mathrm{was} \mathrm{added} \mathrm{to} \mathrm{each} 20 \mu \mathrm{l}$ droplet. When required, laser-assisted fertilization was carried out using a Fertilase $670 \mathrm{~nm}$ wavelength laser system (MTM Medical Technologies, Montreux, Switzerland) to create a $5-10 \mu \mathrm{m}$ hole in the zona. Oocytes were then maintained at $37^{\circ} \mathrm{C}$ in $6 \% \mathrm{CO}_{2}, 5 \% \mathrm{O}_{2}$ and $89 \% \mathrm{~N}_{2}$. Twenty four hours after the sperm were added, oocytes were scored for development to the two-cell stage. Those embryos that had cleaved were transferred to G1 medium (Gardner \& Lane 2004) and cultured for a further $24 \mathrm{~h}$ before being transferred to G2 medium (Gardner \& Lane 2004) for an additional $48 \mathrm{~h}$. On day 4 and day 5, embryos were scored for developmental stages. Cell number and allocation to the trophectoderm and inner cell mass were assessed using differential cell staining (Hardy et al. 1989). Statistical analysis was performed using either Students unpaired $t$-test or ANOVA followed by Bonferonni comparison.

\section{Results}

Current vitrification protocols typically employ both DMSO and EG. To investigate the effect of these two cryoprotectants on intracellular calcium concentration, mouse oocytes were loaded with the ratiometric fluorescent indicator, Indo-1 and the cryoprotectant solution rapidly applied. Both $1.5 \mathrm{~mol} \mathrm{I}^{-1}$ DMSO and EG caused transient increases in intracellular calcium that increased the fluorescence ratio $2-3$ times and lasted for approximately $5 \mathrm{~min}$ (Fig. $1 \mathrm{a}, \mathrm{b}$ ). The ratio increase caused by both cryoprotectants was similar to the initial increase caused by sperm entry, although slightly longer in duration (Fig. 1c). It appears that the kinetics of calcium release are different as the mean base-to-peak ratio for DMSO $(3.20 \pm 0.16)$ was elevated compared with EG $(2.66 \pm 0.18 ; P=0.06)$.

In an attempt to reduce the amount of calcium being released, oocytes were incubated in calcium-free media prior to application of the cryoprotectants (again in calcium-free media). The effect of calcium-free treatment was different for DMSO compared with EG (Fig. 1d,e). The DMSO-induced increase in calcium was unaffected by the absence of extracellular calcium. The mean baseto-peak ratio increase was not significantly different for DMSO challenge in the presence or absence of calcium (3.20 \pm 0.16 and $3.11 \pm 0.15$ respectively; $P=0.68$; Fig. 2a). In contrast, the EG response was significantly decreased by removal of calcium $(2.66 \pm 0.18$ and $1.58 \pm 0.1$ respectively; $P=0.0001$; Fig. $2 b$ ).

It has previously been reported that removing calcium from the cryoprotectant medium reduces the cytotoxicity of high levels of EG (Takahashi et al. 2004). Therefore, reducing the increase in intracellular calcium in response to cryoprotectant exposure offers an advantage in improving cell survival. Since an increase in calcium normally triggers cortical granule release, which leads to zona hardening, it was determined whether removing extracellular calcium also reduced zona hardening following cryoprotectant exposure during vitrification. Oocytes were either vitrified in the presence or absence of extracellular calcium. Zona hardening was then assessed by monitoring the time taken for zona dissolution in 1\% chymotrypsin (Matson et al. 1997). Figure 3a shows that vitrified oocytes in the presence of calcium have a zona pellucida that takes 6 times longer to dissolve than non-vitrified control oocytes. However, removing extracellular calcium significantly reduces (by $40 \%$ ) the zona hardening induced during vitrification.

To demonstrate that it is indeed a rise in intracellular calcium that triggers zona hardening during the vitrification procedure and not a direct physical effect, oocytes were loaded with the calcium chelator, BAPTA-AM, which has been used to block calcium increases at fertilization and mitosis entry in mouse embryos (Kono et al. 1996, Tombes et al. 1992). By directly preventing an increase in intracellular calcium with BAPTA, zona 
(a)

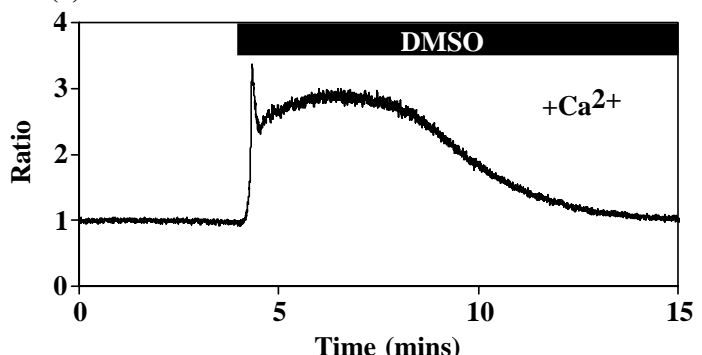

(b)

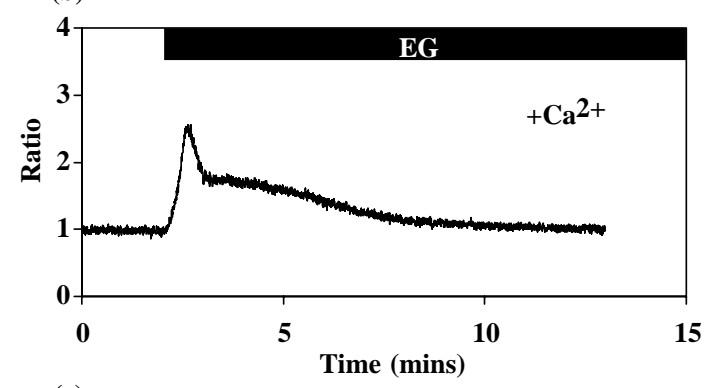

(c)

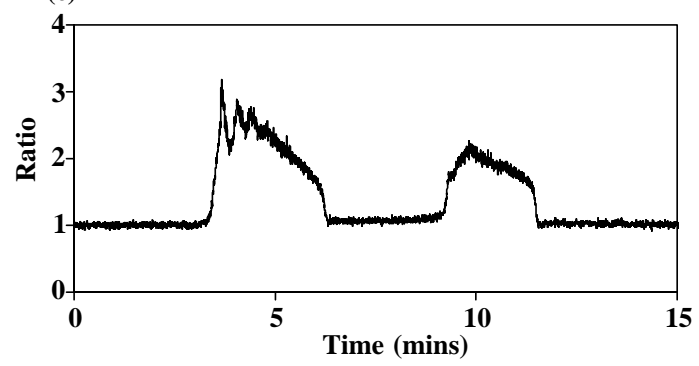

(d)

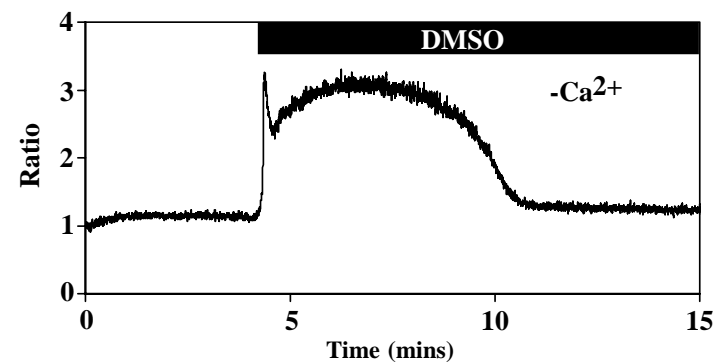

(e)

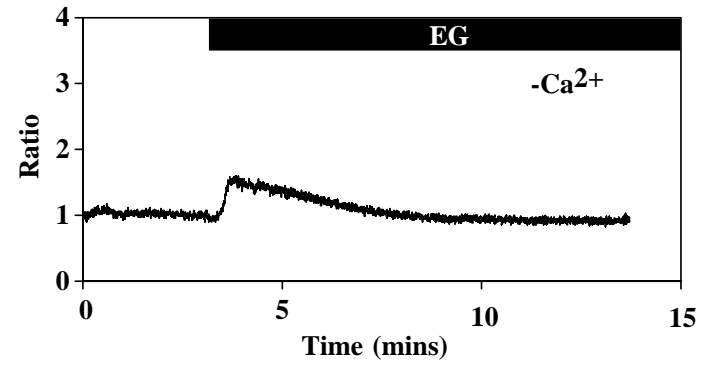

Figure 1 The effect of DMSO and EG on intracellular calcium in metaphase II (MII) mouse oocytes. Mouse oocytes loaded with Indo-1 were held in a heated chamber $\left(37^{\circ} \mathrm{C}\right)$ and changes in calcium were monitored with a PMT (photomultiplier tube)-based system. Oocytes were treated with $1.5 \mathrm{~mol} \mathrm{I}^{-1}$ DMSO (a, d) or EG (b, e) in the presence or absence of calcium ( $n=$ greater than 12 for each treatment, with at least 6 replicates). (c) The initial increase in calcium triggered by sperm at fertilization.

hardening was further reduced to levels not significantly different from non-vitrified oocytes (Fig. 3a).

A previous report has suggested that it is part of the freeze/thaw process and not cryoprotectant exposure that physically alters the zona pellucida (Wood et al. 1992). To examine this, oocytes were treated with the same vitrifcation regime (i.e. vitrification and warming solutions) without exposure to liquid nitrogen and
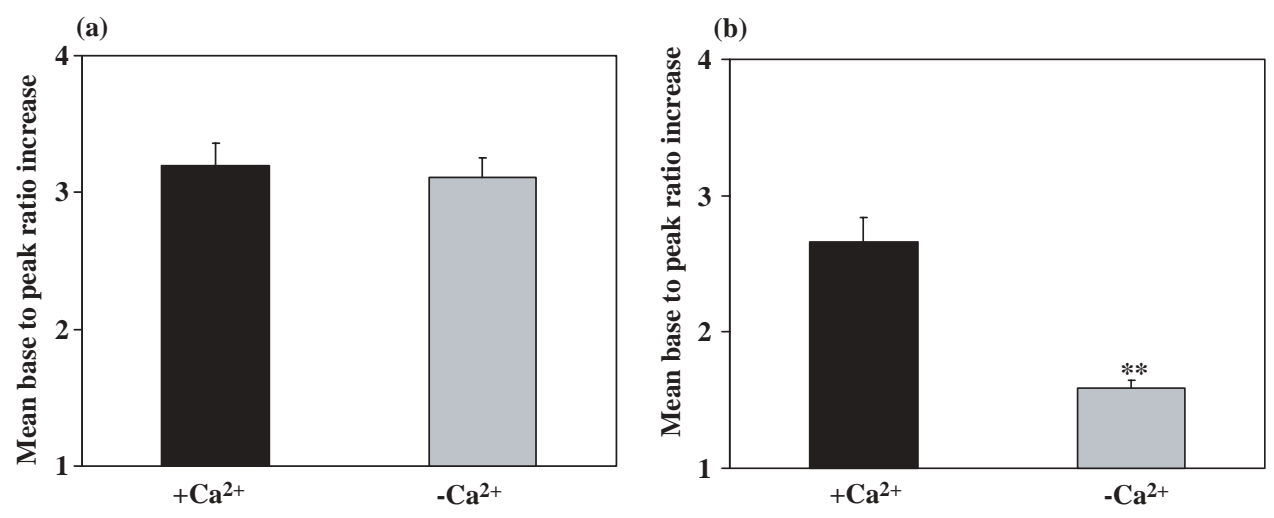

Figure 2 Mean base-to-peak ratio increase following DMSO and EG exposure in the presence and absence of extracellular calcium. The increase in calcium was measured by the fold-increase in ratio from base to peak ( $n=$ greater than 12 for each treatment, with at least 6 replicates). (a) The difference between DMSO challenge in the presence or absence of calcium was insignificant $(P=0.68)$, whereas (b) EG showed a significant reduction in calcium release in the absence of extracellular calcium. ${ }^{* *} P=0.0001$. 
(a)

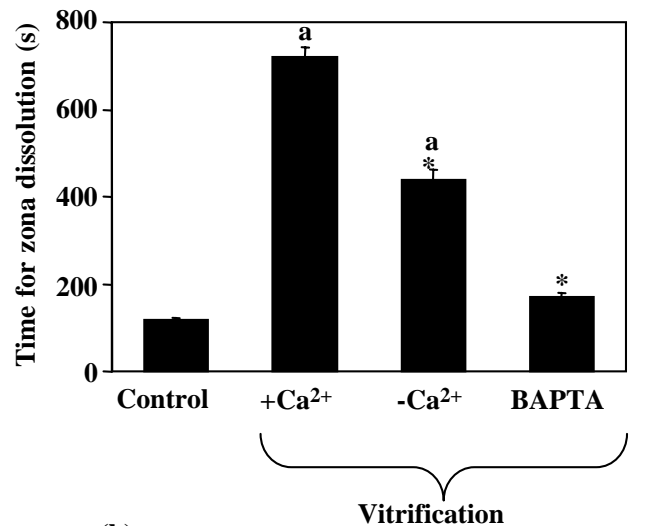

(b)

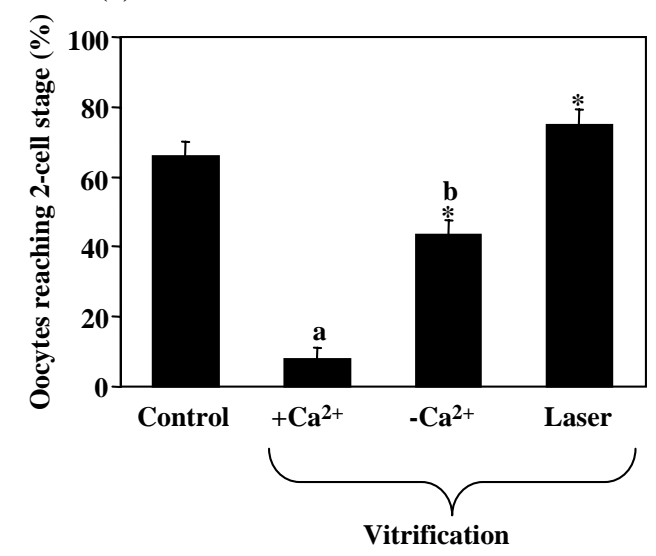

Figure 3 The effect of removing extracellular calcium from the vitrification medium on zona hardening and subsequent fertilization. Oocytes were collected from F1 hybrid (C57BL/6 × CBA) female mice at $12.5 \mathrm{~h}$ post-hCG. (a) Oocytes were divided into 3 treatment groups and a non-vitrified control. Following vitrification in the presence or absence of calcium or treatment with BAPTA-AM, the oocytes were incubated in $1 \%$ chymotrypsin to assess the level of zona hardening. The time taken for the zona to completely disappear was recorded for each treatment $(n=$ greater than 60 eggs for each treatment, with at least 3 replicates). Calcium-free vitrification and BAPTA-AM treatment significantly reduced zona hardening, when compared to vitrification with calcium $(* ; P=0.001)$. Zona hardening following vitrification with or without calcium was statistically different from control (a; $P=0.001)$. (b) Following vitrification ( $>95 \%$ survival rate) oocytes were fertilized $15 \mathrm{~h}$ post-hCG in G-FERT. Laser-assisted fertilization (Laser) was included as an additional treatment group. The ability of the sperm to penetrate the zona and fertilize the oocyte was assessed by monitoring the number of two-cell stage embryos $24 \mathrm{~h}$ after addition of sperm ( $n=$ greater than 250 eggs for each treatment). Calcium-free vitrification and laser-assistance significantly increased fertilization and development to the two-cell stage, when compared to vitrification with calcium $(* ; P=0.001)$. Development to the two-cell stage, following vitrification with or without calcium was statistically different from control ( $\mathrm{a} ; P=0.001, \mathrm{~b} ; P=0.01$ ).

subsequent vitrification. The time for zona dissolution following this treatment was $780.2 \pm 26.42 \mathrm{~s}$, indicating that the effect on the zona is caused by the cryoprotectant solution and not by the freeze/thaw process.

The outcome of zona hardening following vitrification is severely reduced fertilization rates with IVF. This is due not only to the zona hardening, but also to a specific change in a sperm binding protein. The zona pellucida glycoprotein (ZP2) becomes converted to the fertilized form, which does not support sperm binding. This has resulted in the use of ICSI or partial zona removal following freezing to permit sperm access to the plasma membrane and fertilization (Carroll et al. 1990, Kazem et al. 1995, Porcu et al. 2000). Since zona hardening is significantly reduced in the absence of extracellular calcium, we wanted to determine if this increased the fertilization rate and subsequent development to the two-cell stage. Oocytes were vitrified in the presence or absence of extracellular calcium and then fertilized in vitro. Development to the two-cell stage was assessed at $24 \mathrm{~h}$. Oocytes vitrified in the presence of calcium had very poor fertilization rates and poor development to the two-cell stage (less than 10\%; Fig. 3b). Removing the extracellular calcium significantly increased the number of oocytes reaching the two-cell stage to a rate that approached the non-vitrified control (Fig. 3b). To show that it was zona hardening that reduced the level of fertilization and development, oocytes that had been vitrified in the presence of calcium had a 5-10 $\mu \mathrm{m}$ hole made in the zona with a laser. When sperm access to the oocyte was permitted with this laserassistance procedure, fertilization and two-cell development were comparable to non-vitrified oocytes (Fig. 3b).

Removing extracellular calcium appears to significantly reduce zona hardening and therefore dramatically improve fertilization rates. To ensure that the removal of calcium during the vitrification procedure does not compromise embryo development, fertilized oocytes were subsequently cultured and monitored for developmental rate to the blastocyst stage and cell number/allocation through differential staining. Oocytes that had been fertilized and developed to two-cell embryos were cultured in sequential media for a total of $96 \mathrm{~h}$. Embryos were scored on day 4 and day 5 for embryo development. The vitrification protocol we used has previously been reported not to affect embryo development or cell number/allocation (Lane \& Gardner 2001). It was found that carrying out calcium-free vitrification did not affect embryo development (Fig. 4a). On day four $39.1 \%$ of control (non-vitrified) embryos had reached the blastocyst stage, which was comparable to the number of embryos following calciumfree vitrification $(37.2 \%)$. On day five the percentage of embryos from the control and calcium-free vitrification treatments that had reached the hatching blastocyst stage was also similar (94.2 and 92.2\% respectively).

Using differential staining (Hardy et al. 1989) cell number and allocation between the trophectoderm (TE) and inner cell mass (ICM) were determined for non-vitrified control embryos and those that were vitrified in calciumfree media. Figure $4 \mathrm{~b}$ shows that as with the regular vitrification protocol the calcium-free treatment had no detrimental effect on TE or ICM numbers. 
(a)

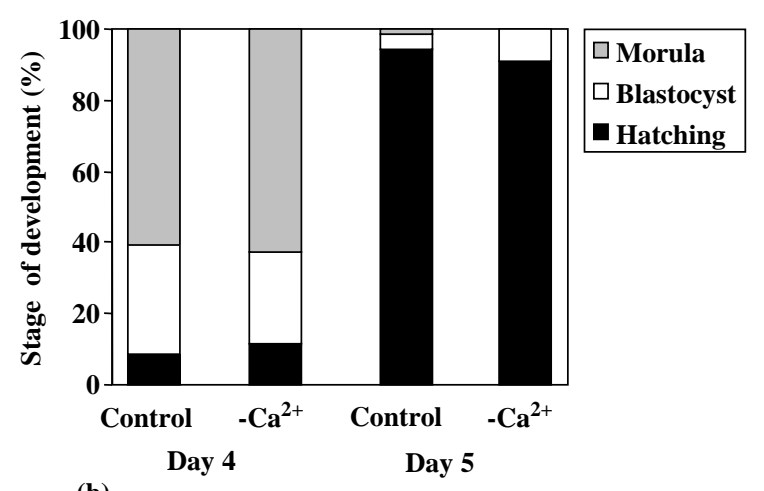

(b)

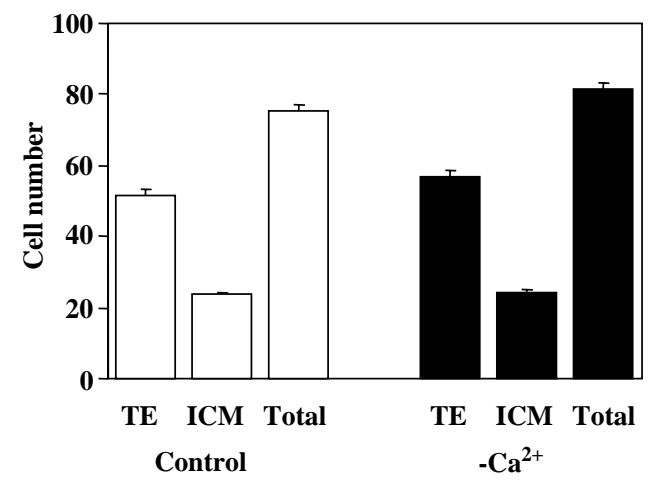

Figure 4 The effect of calcium-free vitrification on embryo development. (a) Two-cell embryos derived from either non-vitrified (control) or calcium-free vitrified oocytes were cultured for 5 days. Embryo development was scored on day 4 and day 5 for morula, blastocyst and hatching blastocyst formation ( $n=$ greater than 140 embryos for each treatment). (b) Following the day 5 score, cell numbers composing the trophectoderm (TE) and inner cell mass (ICM) were determined using differential cell staining $(n=$ greater than 60 for each treatment). No statistical differences were observed.

\section{Discussion}

Despite the high success rate of embryo cryopreservation and subsequent clinical pregnancies, efficient human oocyte cryopreservation remains elusive. Pronucleate stage embryos have been frozen using numerous techniques and different mammalian species, which suggests that the surface area to volume ratio, per se, does not account for the problematic nature of oocyte freezing (Coticchio et al. 2004). The permeability of the oocyte to cryoprotectants and their ability to replace intracellular water is another well documented consideration (Pfaff et al. 1998, Pedro et al. 2005), but rarely is the cell cycle stage contemplated. The oocyte is primed for activation and completion of meiosis, which is triggered by the sperm. The sperm delivers the signal to resume development by introducing a sperm-specific protein upon sperm-egg fusion (Saunders et al. 2002). The protein (phospholipase $\mathrm{C}$ zeta) triggers calcium oscillations that last several hours and control a number of activation events such as cortical granule exocytosis (block to polyspermy) and maturation promoting factor (MPF) down-regulation (Lorca et al. 1991, Kline \& Kline 1992, Nixon et al. 2002, Marangos \& Carroll 2004) which allows completion of meiosis. Precocious initiation of cortical granule exocytosis has already been demonstrated during cryopreservation (Carroll et al. 1990). Together with the observation that the cryoprotectant agent DMSO causes zona hardening through cortical granule release, which is a calcium-dependent event, the aim of this study was to investigate if vitrification affects intracellular calcium.

Previous studies have reported that $1.5 \mathrm{moll}^{-1}$ 1,2-propanediol increased intracellular calcium in aged mouse oocytes (Litkouhi et al. 1999) and high levels of EG caused sustained calcium increases (Takahashi et al. 2004). However, to our knowledge no study has investigated the effect of cryoprotectants (DMSO and EG) at levels commonly used for vitrification on young oocytes $(14-17 \mathrm{~h}$ post-h(G). By loading mouse oocytes with a fluorescent calcium indicator and exposing them to DMSO and EG, we have found that both of these agents cause a dramatic transient increase in intracellular calcium. The amplitude of the calcium increase caused by the cryoprotectants is comparable to the initial increase triggered at fertilization, but lasts approximately 50\% longer in duration (Saunders et al. 2002). DMSO appeared to induce a larger and more sustained increase in calcium compared with EG, which may be attributable to the higher permeability of the oocyte to DMSO (Paynter 2005). The exact mechanism for the cryoprotectant-induced calcium increase is unknown. The lipophilic properties of DMSO and EG would be expected to have a non-specific effect on the plasma membrane and other internal membranes such as the endoplasmic reticulum, which would lead to either calcium influx and/or calcium release from internal stores. However, the osmotic contraction induced by cryoprotectants might also contribute to the increase in intracellular calcium.

Removing external calcium failed to affect the intracellular calcium increase caused by DMSO, which suggests that internal stores, such as the endoplasmic reticulum, are the source of the rise. This is in agreement with observations with several different cell lines (Morley \& Whitfield 1993). In contrast, observations presented here show that with EG, removal of external calcium significantly reduces the intracellular calcium increase, which suggests the majority of the EG-induced calcium increase is via influx across the plasma membrane from the medium.

Earlier studies using a fluorescent lectin binding assay to assess cortical granule exudate reported no premature release following freezing of mouse or human oocytes (Wood et al. 1992, Gook et al. 1993). However, as discussed by Wood and colleagues (1992) it is possible that the assay may not be sensitive enough to detect a lower threshold of release or the population of cortical granules released may not contain the appropriate binding substrate. Since the amount of calcium released is comparable to that at fertilization, it would be capable of causing cortical granule exocytosis, which would explain zona hardening. This conclusion is also in agreement with the findings of 
Vincent and colleagues (1990), who demonstrated that the oocyte must be present for zona hardening to occur following exposure to DMSO. The data presented here show that cryoprotectant exposure alone causes zona hardening. Since introduction of the calcium chelating agent, BAPTA, prevents zona hardening, it appears that the cryoprotectants used increase intracellular calcium to levels sufficient to induce cortical granule release and subsequent zona hardening. Removing calcium during vitrification significantly reduces the degree of zona hardening, which dramatically improves fertilization and development to the two-cell stage.

Although zona hardening and its negative effect on fertilization rates can be circumvented through ICSI or partial zona removal, cortical granule release is but one of the initial activation events. A large increase in calcium might also be detrimental for further embryo development by affecting cell cycle proteins such as MPF whose downregulation is normally triggered by the calcium oscillations at fertilization (Lorca et al. 1991, Marangos \& Carroll 2004). Calcium is a ubiquitous signaling agent that is involved in a number of biological processes, so strict homeostatic regulation of release is critical (for review see Berridge et al. 1998). A sustained level of micromolar calcium is sufficient to cause the inappropriate activation of calcium-dependent enzymes such as proteases and phospholipases, which can have severe cellular consequences (Orrenius et al. 2003). Furthermore, oocytes activated with high frequency calcium oscillations can undergo apoptosis (Gordo et al. 2000, 2002). A large increase in intracellular calcium caused by cryoprotectants may therefore decrease viability and explain the low efficiency of oocyte cryopreservation. Further support for this idea is provided by removing extracellular calcium and introducing BAPTA to reduce the intracellular calcium rise during cryoprotectant exposure. Takahashi and colleagues (2004) demonstrated that reducing the calcium increase in mouse oocytes with such an approach significantly reduced the calcium rise caused by $40 \%$ EG (for $3 \mathrm{~min}$ ), which, in turn, increased the number of intact oocytes from $0 \%$ to $100 \%$.

The results presented here demonstrate that both DMSO and EG cause a transient increase in intracellular calcium. This increase in calcium is responsible for zona hardening and explains the requirement for zona removal or ICSI to permit fertilization. Zona hardening, caused by exposure to the cryoprotectant, can be overcome by inclusion of bovine serum albumin (BSA) in the medium (George et al. 1992). This, together with the employment of lower temperatures during cryoprotectant exposure, would account for the apparent lack of zona hardening and high fertilization rates reported in some previous studies (Carroll et al. 1990, Hotamisligil et al. 1996, dela Pena et al. 2001). It is thought that the active component in BSA is fetuin (George \& Johnson 1993) which presumably acts as either a competitive substrate for proteolytic enzymes released from the cortical granules or as a direct inhibitor.
However, in human IVF a more defined system is required and human serum albumin has been shown not to afford the same protection as BSA (George \& Johnson 1993). Lowering the temperature during cryoprotectant exposure prevents zona hardening, most likely through the decrease in temperature-sensitive enzymatic activity and cellular function, but by carrying out the procedure at $37^{\circ} \mathrm{C}$ it alleviates potential cooling injury to the cytoskeleton (Pickering \& Johnson 1987, Pickering et al. 1990).

The data presented here demonstrate that the cryoprotectants, EG and DMSO, increase intracellular calcium, which leads to the induction of zona hardening. Subsequent removal of calcium from the vitrification medium facilitated IVF and development to the two-cell stage at a rate approaching that of control (non-vitrified) oocytes. The calcium-free treatment did not affect embryo development rates or cell number/allocation in the blastocyst, which suggests that the removal of calcium during cryopreservation is not detrimental. In this present study we wished to examine the effect of calcium-free vitrification on a common protocol that used EG and DMSO. However, the fact that the response to DMSO challenge was unaffected by removing extracellular calcium suggests that DMSO should either be omitted from the cryoprotectant solutions or reduced to a concentration that does not dramatically increase intracellular calcium. The kind of analysis presented here provides the opportunity for further experiments, which include using the measurement of calcium during cryoprotectant challenge to empirically determine the optimum concentration and duration of exposure for vitrification protocols that minimize the increase in oocyte intracellular calcium. By carrying out such studies it is anticipated that not only will zona hardening be significantly reduced, but also that normal cell function will be facilitated allowing IVF and thereby increasing the efficiency of oocyte cryopreservation.

\section{Acknowledgements}

The authors wish to thank Laura Reed for her assistance and Vitrolife for their support of these studies. The authors declare that there is no conflict of interest that would prejudice the impartiality of this scientific work.

\section{References}

Berridge MJ, Bootman MD \& Lipp P 1998 Calcium - a life and death signal. Nature 395 645-648.

Carroll J, Depypere H \& Matthews CD 1990 Freeze-thaw-induced changes of the zona pellucida explains decreased rates of fertilization in frozen-thawed mouse oocytes. Journal of Reproduction and Fertility $89253-259$.

Chen C 1986 Pregnancy after human oocyte cryopreservation. Lancet $1884-886$.

Coticchio G, Bonu MA, Borini A \& Flamigni C 2004 Oocyte cryopreservation: a biological perspective. European Journal of Obstetrics, Gynecology and Reproductive Biology 115 (Supp 1) S2-S7.

Falcone T, Attaran M, Bedaiwy MA \& Goldberg JM 2004 Ovarian function preservation in the cancer patient. Fertility and Sterility $\mathbf{8 1}$ $243-257$. 
Gardner DK \& Lane M 2004 Culture of the mammalian preimplantation embryo. In A Laboratory Guide to the Mammalian Embryo, ch 3, pp 41-61. Eds DK Gardner, M Lane \& A Watson. Oxford: Oxford University Press.

Gardner DK, Lane M, Stevens MT \& Schoolcraft WB 2003 Changing the start temperature and cooling rate in a slow-freezing protocol increases human blastocyst viability. Fertility and Sterility $\mathbf{7 9}$ 407-410.

George MA, Johnson MH \& Vincent C 1992 Use of fetal bovine serum to protect against zona hardening during preparation of mouse oocytes for cryopreservation. Human Reproduction 7 $408-412$.

George MA \& Johnson MH 1993 Use of bovine serum substitutes for the protection of the mouse zona pellucida against hardening during cryoprotectant addition. Human Reproduction 8 1898-1900.

Gook DA, Osborn SM \& Johnston WI 1993 Cryopreservation of mouse and human oocytes using 1,2-propandiol and the configuration of meiotic spindle. Human Reproduction 8 1101-1119.

Gordo AC, Wu H, Li He C \& Fissore RA 2000 Injection of sperm cytosolic factor into mouse metaphase II oocytes induces different developmental fates according to the frequency of $\left[\mathrm{Ca}^{2+}\right]_{\mathrm{i}}$ oscillations and oocyte age. Biology of Reproduction 62 1370-1379.

Gordo AC, Rodrigues P, Kurokawa M, Jellerette T, Exley GE, Warner C \& Fissore R 2002 Intracellular calcium oscillations signal apoptosis rather than activation in in vitro aged mouse eggs. Biology of Reproduction 66 1828-1837.

Hardy K, Handyside AH \& Winston RM 1989 The human blastocyst: cell number, death and allocation during late preimplantation development in vitro. Development 107 597-604.

Hotamisligil S, Toner M \& Powers RD 1996 Changes in membrane integrity, cytoskeletal structure, and developmental potential of murine oocytes after vitrification in ethylene glycol. Biology of Reproduction 55 161-168.

Kasai M \& Mukaida T 2004 Cryopreservation of animal and human embryos by vitrification. Reproductive Biomedicine Online 9 164-170.

Kazem R, Thompson LA, Srikantharajah A, Laing MA, Hamilton MPR \& Templeton A 1995 Cryopreservation of human oocytes and fertilization by two techniques: in vitro fertilization and intracytoplasmic injection. Human Reproduction 10 2650-2654.

Kline D \& Kline J 1992 Repetitive calcium transients and the role of calcium in exocytosis and cell cycle activation in the mouse egg. Developmental Biology 149 80-89.

Kono T, Jones KT, Bos-Mikich A, Whittingham DG \& Carroll J 1996 A cell cycle-associated change in $\mathrm{Ca}^{2+}$ releasing activity leads to the generation of $\mathrm{Ca}^{2+}$ transients in mouse embryos during the first mitotic division. Journal of Cell Biology 132 915-923.

Lane M \& Gardner DK 2001 Vitrification of mouse oocytes using a nylon loop. Molecular Reproduction and Development 58 342-347.

Lane M \& Gardner DK 2004 Preparation of gametes, in vitro maturation, in vitro fertilization, and embryo recovery and transfer. In $A$ Laboratory Guide to the Mammalian Embryo, ch 2, pp 24-40. Eds DK Gardner, M Lane \& A Watson. Oxford: Oxford University Press.

Lawrence Y, Whitaker M \& Swann K 1997 Sperm-egg fusion is the prelude to the initial $\mathrm{Ca}^{2+}$ increase at fertilization in the mouse. Development 124 233-241.

Leibo SP 2004 Cryopreservation of mammalian oocytes. In Preservation of Fertility, ch 11, pp 141-155. Eds T Tulandi \& RG Gosden. London: Taylor \& Francis Group.

Liebermann J 2003 Recent developments in human oocyte, embryo and blastocyst vitrification: where we are now? Reproductive Biomedicine Online 7 623-633.

Litkouhi B, Winlow W \& Gosden RG 1999 Impact of cryoprotective agent exposure on intracellular calcium in mouse oocytes at metaphase II. Cryoletters 20 353-362.

Lorca T, Galas S, Fesquet D, Devault A, Cavadore JC \& Doree M 1991 Degradation of the proto-oncogene product p39mos is not necessary for cyclin proteolysis and exit from meiotic metaphase: requirement for a $\mathrm{Ca}^{2+}$-calmodulin dependent event. EMBO Journal 10 2087-2093.

Marangos P \& Carroll J 2004 Fertilization and Ins $\mathrm{P}_{3}$-induced $\mathrm{Ca}^{2+}$ release stimulate a resistant increase in the rate of degradation of cyclin B1 specifically in mature mouse oocytes. Developmental Biology 272 26-38.

Matson PL, Graefling J, Junk SM, Yovich JL \& Edirisinghe RW 1997 Cryopreservation of oocytes and embryos: use of a mouse model to investigate effects upon zona hardness and formulate treatment strategies in an in vitro fertilization programme. Human Reproduction 12 1550-1553.

Morley P \& Whitfield JF 1993 The differentiation inducer, dimethyl sulfoxide, transiently increases the intracellular calcium ion concentration in various cell types. Journal of Cellular Physiology 156 219-225.

Mukaida T, Nakamura S, Tamiyama T, Wada S, Kasai M \& Takahashi K 2001 Successful birth after transfer of vitrified human blastocysts with the use of cryoloop containerless technique. Fertility and Sterility 76 618-620.

Mukaida T, Takahashi K \& Kasai M 2002 Blastocyst cryopreservation: ultrarapid vitrification using cryoloop technique. Reproductive Biomedicine Online 6 221-225.

Nixon VL, Levasseur M, McDougall A \& Jones KT $2002 \mathrm{Ca}^{2+}$ oscillations promote APC/C-dependent cyclin B1 degradation during metaphase arrest and completion of meiosis in fertilizing mouse eggs. Current Biology 12 746-750.

Orrenius S, Zhivotovsky B \& Nicotera P 2003 Regulation of cell death: the calcium-apoptosis link. Nature Reviews of Molecular and Cellular Biology 4 552-565.

Paynter S 2005 A rational approach to oocyte cryopreservation. Reproductive BioMedicine Online 10 578-586.

Pedro PB, Yokoyama E, Zhu SE, Yoshida N, Valdez DM Jr, Tanaka M, Edashige K \& Kasai M 2005 Permeability of mouse oocytes and embryos at various developmental stages to five cryoprotectants. Journal of Reproduction and Development 51 235-246.

dela Pena EC, Takahashi Y, Atabay EC, Katagiri AS \& Nagano M 2001 Vitrification of mouse oocytes in ethylene glycol-raffinose solution: effects of preexposure to ethylene glycol or raffinose on oocyte viability. Cryobiology 42 103-111.

Pfaff RT, Liu J, Gao D, Peter AT, Li TK \& Crister JK 1998 Water and DMSO membrane permeability characteristics of in vivo- and in vitro-derived and cultured murine oocytes and embryos. Molecular Human Reproduction 4 51-59.

Pickering SJ \& Johnson MH 1987 The influence of cooling on the organization of the meiotic spindle of the mouse oocyte. Human Reproduction 2 207-216.

Pickering SJ, Braude PR, Johnson MH, Cant A \& Currie J 1990 Transient cooling to room temperature can cause irreversible distribution of the meiotic spindle in the human oocyte. Fertility and Sterlitiy 54 102-108.

Porcu E, Fabbri R, Damiano G, Giunchi S, Fratto R, Ciotti PM, Venturoli S \& Flamigni C 2000 Clinical experience and applications of oocyte cryopreservation. Molecular and Cellular Endocrinology $16933-37$.

Saunders CM, Larman MG, Parrington J, Cox LJ, Royse J, Blayney LM, Swann K \& Lai FA 2002 PLC : a sperm-specific trigger of $\mathrm{Ca}^{2+}$ oscillations in eggs and embryo development. Development $1291-12$.

Stachecki JJ \& Cohen J 2004 An overview of oocyte cryopreservation. Reproductive Biomedicine Online 9 152-163.

Steponkus PL, Myers SP, Lynch DV, Gardner L, Bronshteyn V, Leibo SP, Rall WF, Pitt RE, Lin TT \& MacIntyre RJ 1990 Cryopreservation of Drosophila melanogaster embryos. Nature 345 $170-172$.

Sun QY 2003 Cellular and molecular mechanisms leading to cortical reaction and polyspermy block in mammalian eggs. Microscopy Research and Technique $61342-348$.

Tahara M, Tasaka K, Masumoto N, Mammoto A, Ikebuchi Y \& Miyake A 1996 Dynamics of cortical granule exocytosis at 
fertilization in living mouse eggs. American Journal of Physiology 270 C1354-C1361.

Takahashi T, Igarashi H, Doshida M, Takahashi K, Nakahara K Tezuka N \& Kurachi H 2004 Lowering intracellular and extracellular calcium contents prevents cytotoxic effects of ethylene glycolbased vitrification solution in unfertilized mouse oocytes. Molecular Reproduction and Development 68 250-258.

Tombes RM, Simerly C, Borisy GG \& Schatten G 1992 Meiosis, egg activation and nuclear envelope breakdown are differentially reliant on $\mathrm{Ca}^{2+}$, whereas germinal vesicle breakdown is $\mathrm{Ca}^{2+}$-independent in the mouse oocyte. Journal of Cell Biology 117 799-811.

Veeck LL 2003 Does the developmental stage at freezing impact on clinical results post-thaw? Reproductive Biomedicine Online $\mathbf{7 9}$ 407-410.

Veeck LL, Bodine R, Clarke RN, Berrios R, Libraro J, Moschini RM, Zaninovic N \& Rosenwaks Z 2004 High pregnancy rates can be achieved after freezing and thawing human blastocysts. Fertility and Sterility 82 1418-1427.
Vincent C, Pickering SJ \& Johnson MH 1990 The hardening effect of dimethyl sulphoxide on the mouse zona pellucida requires the presence of an oocyte and is associated with a reduction in the number of cortical granules present. Journal of Reproduction and Fertility $89253-259$.

Vincent C, Turner K, Pickering SJ \& Johnson MH 1991 Zona pellucida modifications in the mouse in the absence of oocyte activation. Molecular Reproduction and Development 28 394-404.

Wood MJ, Whittingham DG \& Lee SH 1992 Fertilization failure of frozen mouse oocytes is not due to premature cortical granule release. Biology of Reproduction 46 1187-1195.

Received 8 July 2005

First decision 25 August 2005

Revised manuscript received 24 September 2005

Accepted 3 October 2005 